\title{
Analisis Penentuan Komoditas Unggulan Subsektor Perkebunan Kecamatan Penajam, Kabupaten Penajam Paser Utara
}

\section{Flagship Commodities of Plantation Subsector In Penajam Disrict, Kabupaten Penajam Paser Utara}

\author{
Sitinur Amaliah ${ }^{\mathrm{a}}$, Dwiana Novianti Tufail ${ }^{\mathrm{a}}$, Mohtana Kharisma Kadria ${ }^{\text {** }}$ \\ ${ }^{a}$ Institut Teknologi Kalimantan, Balikpapan, Indonesia
}

\begin{abstract}
Abstrak
Pemanfaatan sumberdaya alam secara optimal menjadi indikator keberhasilan pengembangan ekonomi salah satunya melalui komoditas subsektor perkebunan. Kecamatan Penajam memiliki potensi terbesar pada sektor pertanian khususnya subsektor perkebunan sebagai arahan pemanfaatan lahan perkebunan seluas 39,707 ha dibandingkan kecamatan lainnya. Dengan potensi lahan yang besar membuat Kecamatan Penajam memiliki peluang untuk meningkatkan pengembangan ekonomi melalui pemanfaatan komoditas subsektor perkebunan. Disisi lain potensi fungsi lahan perkebunan yang tinggi, terdapat pemanfaatan yang belum optimal pada subsektor perkebunan. Sehingga diperlukan upaya pengembangan ekonomi sebagai identifikasi pengembangan wilayah berbasis ekonomi yang dapat dilakukan dengan penentuan komoditas unggulan subsektor perkebunan di Kecamatan Penajam. Penelitian ini bertujuan untuk mengetahui komoditas unggulan subsektor perkebunan sebagai upaya pengembangan ekonomi di Kecamatan Penajam, Kabupaten Penajam Paser Utara dengan menggunakan metode analisis kuantitatif terhadap data sekunder yaitu hasil produksi komoditas perkebunan tahun 2014 - 2019. Adapun tahapan analisis terdiri dari: 1) Menentukan komoditas basis/non basis subsektor perkebunan menggunakan teknik analisa Location Quotioent $(L Q), 2)$ Menentukan nilai pertumbuhan dan daya saing menggunakan teknik Shift Share Analysis (SSA), 3) Menentukan komoditas unggulan dengan teknik analisa komulatif hasil LQ dan SSA. Berdasarkan hasil penelitian didapatkan bahwa komoditas unggulan subsektor di Kecamatan Penajam yaitu komoditas kelapa dan komoditas kelapa sawit.
\end{abstract}

Kata kunci: Pengembangan Ekonomi; Komoditas Unggulan; Perkebunan.

\begin{abstract}
Utilization of resources optimally to commodities of plantation subsector can be used as indicator to determine the economic development. In Penajam District, has potency in the agricultural sector, especially a plantation subsector with the largest proportion land use directives at 39,707 ha bigger than the other district. With this potential, Penajam District has a greater opportunity to improve economic development by using yields plantation subsector. On the other side, there is unoptimal utilization in the plantation subsector. Thus, economic development efforts can be used as identification for economic regional with determining of superior commodity of plantation subsector in Penajam District. This study aims to determine the superior commodity of plantation subsector as an economic development effort in Penajam by using quantitative analysis method of secondary data namely plantation commodity production in 2014 - 2019. The analytical methods that used are 1) determination of basis and non-basis use Location Quotient Analysis (LQ) 2) determination of development value and competitiveness value use Shift Share Analysis (SSA), 3) achieved through the determination of superior commodities use recapitulation of LQ and SSA. The results showed that flagship commodities of plantation for economic development in Penajam is Coconut and palm oil.
\end{abstract}

Keyword: Economic Development; Flagship Commodities; Plantation.

\footnotetext{
* Corresponding author. Sitinur Amaliah.

E-mail address: 08161079@student.itk.ac.id.
} 


\section{Pendahuluan}

Pelaksanaan pengembangan ekonomi melalui pemanfaatan terhadap satu sektor potensial akan menghasilkan konsep pembangunan wilayah secara mendetail. Secara garis besar Negara Indonesia masih didominasi pada sektor pertanian dimana sektor ini diperlukan upaya peningkatan sehingga menghasilkan pemanfaatan sumberdaya alam secara maksimal. Menurut Riyadi dan Andri (2015) nilai kontribusi sektor pertanian dalam pembentukan perkembangan ekonomi daerah merupakan bentuk dari beberapa subsektor yang terdiri dari; perkebunan, peternakan, tanaman pangan, kehutanan dan perikanan. Sehingga kontribusi pada sektor pertanian banyak didukung terhadap subsektor yang terdapat didalamnya termasuk juga subsektor perkebunan. Berdasarkan hal tersebut, pengembangan wilayah melalui pemanfaatan sumberdaya alam dapat mendorong perekonomian wilayah secara cepat karena menggunakan hubungan fungsional terhadap aspek fisik dan ekonomi pada wilayah tersebut.

Kabupaten Penajam Paser Utara merupakan salah satu Kabupaten di Provinsi Kalimantan Timur yang memiliki potensi sumberdaya alam melimpah pada sektor pertanian. Memiliki luas wilayah yang tinggi, Kabupaten Penajam Paser Utara atau Kab. PPU memiliki total lahan secara keseluruhan terhadap sektor pertanian mencapai 194.638,4 Ha pada tahun 2018 sehingga menjadikan Kab. PPU memiliki potensi terhadap sektor pertanian. Dalam pengguna lahan pada sektor pertanian di Kabupaten Penajam Paser Utara, subsektor perkebunan menjadi subsektor yang memiliki potensi jumlah lahan terbesar kemudian diikuti pada subsektor tanaman pangan. Hal tersebut sejalan dengan nilai sektor pertanian Kab. PPU menjadi sektor kedua setelah sektor pertambangan dan penggalian yang memiliki kontribusi besar terhadap perkembangan ekonomi daerah (Database Ekonomi Kab. PPU, 2018). Berdasarkan nilai PDRB Kabupaten Penajam Paser Utara terhitung dari tahun 2015-2019 secara keseluruhan memiliki kinerja yang mengalami peningkatan mencapai 2,40 persen. Namun, pada tahun 2019 nilai pertumbuhan ekonomi pada kategori pertanian mengalami penunrunan. Pertumbuhan yang semakin meningkat kemudian tidak sepenuhnya dapat memberikan kontribusi atau pengaruh besar terhadap perkembangan ekonomi secara keseluruhan sehingga diperlukan upaya agar tidak terjadi pergeseran kegiatan perekonomian di Kabupaten Penajam Paser Utara.

Dengan potensi lahan yang cukup luas terhadap subsektor perkebunan di Kab. PPU dapat digunakan sebagai upaya pencegahan terjadi pergeseran perekonomian sektor pertanian di Kab. PPU. Hal tersebut didukung dengan arahan pemanfaatan untuk perkebunan terbesar di seluruh wilayah kabupaten yaitu pada Kecamatan Penajam dengan proporsi luasan terbesar (39,707 ha) dibandingkan pada Kecamatan Sepaku (30,273 ha), Kecamatan Balulu (23,337 ha) dan Kecamatan Waru (20,399 ha) (Widjayatnika $d k k$, 2017). Sehingga berdasarkan hal tersebut, Kecamatan Penajam dipilih menjadi wilayah studi penelitian yang memiliki potensi subsektor perkebunan yang tinggi.

Dalam melakukan pencegahan terjadi pergeseran terhadap kegiatan perekonomian Kabupaten Penajam Paser Utara, maka dapat dilakukan upaya melalui pendekatan pengembangan komoditas unggulan. Proses analisis komoditas unggulan kemudian menjadi tahapan identifikasi potensi sumberdaya alam pada wilayah Kecamatan Penajam melalui peningkatan komoditas subsektor perkebunan. Berdasarkan penelitian terdahulu oleh Wulandari dan Kemal (2016) dalam Peran Kajian Komoditas Unggulan Sub-Sektor Perkebunan di Provinsi Jambi dilakukan analisis sektor basis dan non-basis untuk mengidentifikasi komoditas unggulan pada Provinsi Jambi. Dalam penelitian ini menghasilkan bahwa komoditas yang memiliki potensi besar terhadap wilayah yaitu kelapa sawit dan memiliki daya saing yang tinggi diantara komoditas lainnya. Hal ini didukung dengan tingkat konsumsi dan nilai jual terhadap komoditas tersebut yang tinggi.

Perkembangan pertumbuhan ekonomi khusus subsektor perkebunan yang terdapat dalam sektor pertanian secara riil dari tahun ke tahun kemudian belum memberikan proporsi terhadap nilai tambah perkembangan ekonomi Kabupaten Penajam Paser Utara. Maka diperlukan pemanfaatan secara optimal pada subsektor perkebunan agar menghasilkan upaya pengembangan ekonomi yang dapat digunakan sebagai konsep pengembangan wilayah melalui pertumbuhan perekonomian wilayah potensial komditas unggulan. 


\section{Metode Penelitian}

Metode penelitian yang digunakan yaitu pendekatan kuantitatif dengan metode pengumpulan data didapatkan melalui survey sekunder. Selain itu penelitian ini didasarkan dengan analisis multivarian yaitu penelitian dengan menggunakan beberapa metode pengukuran sebagai penentuan terhadap tujuan penelitian (Rencher, 2002). Data sekunder terdiri dari studi literatur dan survey instasional untuk mendapatkan data hasil setiap komoditas subsektor perkebunan di Kecamatan Penajam. Adapun data yang digunakan dalam penelitian ini diantaranya yaitu data administrasi wilayah, data produksi seluruh komoditas subsektor perkebunan di Kecamatan Penajam yang terhitung dari tahun 2015 - 2019. Tujuan penelitian yaitu menentukan komoditas unggulan subsektor perkebunan sebagai pengembangan wilayah di Kecamatan Penajam, Kabupaten Penajam Paser Utara. Dalam mencapai tujuan tersebut, tahapan analisis terdiri dari: 1) Menentukan komoditas basis/non basis subsektor perkebunan menggunakan teknik analisa Location Quotioent $(L Q)$, 2) Menentukan nilai pertumbuhan dan daya saing menggunakan teknik Shift Share Analysis (SSA), 3) Menentukan komoditas unggulan dengan teknik analisa komulatif hasil LQ dan SSA.

\subsection{Analisis Jenis Komoditas Basis dan Non-Basis}

Penentuan jenis komoditas dilakukan dengan teknik analisa Location Quotient (LQ). Kemudian dalam unit analisis yang digunakan yaitu jumlah panen komoditas pada 23 Kelurahan dan Desa yang berada di Kecamatan Penajam. maka digunakan jumlah hasil produksi komoditas setiap unit analisis yaitu Kelurahan dan Desa di Kecamatan Penajam, sehingga persamaan yang digunakan menurut Wulandari (2015) yaitu sebagai berikut:

$$
L Q=\frac{V i k / V k}{V i p / V p}
$$

Kriteria: Vik : Hasil produksi komoditas i pada Kelurahan dan Desa

$V k \quad$ : Hasil produksi seluruh komoditas di Kelurahan dan Desa

Vip : Hasil produksi komoditas i pada Kecamatan Penajam

$V p \quad$ : Hasil produksi seluruh komoditas pada Kecamatan Penajam

Berdasarkan hasil perumusan $L Q$, maka output nilai suatu kegiatan pada suatu wilayah penelitian dapat diasumsikan sebagai berikut:

a) Nilai LQ di sektor i $=1$, Hal ini berarti laju pertumbuhan sektor i di Kelurahan dan Desa tersebut adalah sama dengan laju pertumbuhan sektor yang sama dalam perekonomian di Kecamatan Penajam,

b) Niai LQ di sektor i > 1, Hal ini sektor i merupakan sektor di Kecamatan Penajam sekaligus merupakan basis,

c) Nilai LQ di sektor i < 1, Hal ini sektor i bukan merupakan sektor daerah Kecamatan Penajam dan bukan merupakan basis (non-basis).

\subsection{Analisis Struktur Ekonomi}

Teknik kuantitatif Shift Share Analysis (SSA) yaitu metode analisis yang memiliki fungsi dalam identifikasi besar tingkat daya saing komoditas penelitian terhadap masing-masing unit analisis. Analisis ini merupakan model lanjutan hasil analisis LQ yang hanya mengahasilkan output potensi basis, sehingga menurut Mustikaningrum dan Widjonarko (2018) analisis Shift Share menggunakan rasio produksi untuk melihat perbandingan produksi subsektor perkebunan yaitu sebagai berikut: 


$$
\begin{aligned}
& \boldsymbol{P P}=\left[\left({ }^{N P b i l a} /{ }_{\text {NPbiba }}\right)-\left({ }^{N P b l a} /{ }_{\text {NPbba }}\right)\right] \times N P \text { cijba } \\
& \boldsymbol{P P W}=\left[\left(\text { NPcijla }_{\text {NPcijba }}\right)-(N P b i l a / N P b i b a)\right] \times N P c i j b a \\
& P B=P P+P P W
\end{aligned}
$$

$$
\begin{aligned}
\text { Kriteria: PP } & \text { : Komponen Pertumbuhan Proporsional } \\
\text { PPW } & \text { : Komponen Pertumbuhan Pangsa Wilayah } \\
\text { PB } & \text { : Pegeseran Bersih } \\
\text { NPbila } & \text { : Produksi komoditas i pada Kelurahan/Desa Tahun } 2019
\end{aligned}
$$$$
\text { NPbiba : Produksi komoditas i pada Kelurahan/Desa Tahun } 2015
$$$$
\text { NPbba : Produksi komoditas i pada Kecamatan Tahun } 2019
$$$$
\text { NPbla : Produksi komoditas i pada Kecamatan Tahun } 2015
$$$$
\text { NPcila : Total produksi subsektor perkebunan Kecamatan Tahun } 2019
$$$$
\text { NPciba : Total produksi subsektor perkebunan Kecamatan Tahun } 2015
$$

Berdasarkan hasil perumusan SSA dengan nilai Pergeseran bersih (PB), maka dapat diketahui output pada suatu wilayah dengan asumsi sebagai berikut:

a) Apabila nilai PB bernilai positif $\mathrm{PB}>0$, maka komoditas i di Kelurahan/Desa j termasuk kelompok pertumbuhan tinggi atau maju (progresif)

b) Apabila nilai $\mathrm{PB}$ bernilai negatif $\mathrm{PB}<0$, maka komoditas i di Kelurahan/Desa j termasuk kelompok pertumbuhan lambat.

\subsection{Penentuan Komoditas Unggulan}

Penentuan komoditas unggulan selanjutnya dihasilkan berdasarkan hasil rekapitulasi terhadap hasil perhitungan $L Q$ dan SSA. Dalam penentuan ini, digunakan indikator hasil analisis $L Q$ dan SSA meliputi komoditas basis dan non-basis, kemampuan daya saing baik, progresif secara kewilayahan, dan rata-rata tingkat pertumbuhan komoditas. Berdasarkan hal tersebut secara perhitungan dapat dinyatakan dengan klasifikasi komoditas unggulan ditunjukkan dengan nilai yang memiliki keunggulan kompatatif dengan nilai $L Q>1$ dan kelompok progresif memiliki nilai $\mathrm{PB}>0$.

\section{Kajian literatur}

\subsection{Pengembangan Wilayah berbasis Ekonomi}

Pengembangan wilayah secara dasar menjadi teori lokasi dengan menitik beratkan kerjasama antar daerah menuju pertumbuhan wilayah optimal. Keberhasilkan tersebut kemudian dipengaruhi terhadap unsur-unsur strategis diantara lain sumberdaya alam, sumberdaya manusia, dan infrastruktur yang memiliki keterkaitan sehingga dapat dikembangkan berdasarkan sinergitas secara maksimal. Dalam pengembangan wilayah, banyak teori dapat digunakan sebagai landasan untuk menjelaskan pentingnya terhadap kegiatan ekonomi. Menurut Ridwan (2016) pengembangan ekonomi merupakan upaya yang dapat mendorong individual dan/atau kelompok untuk memperbaiki akses dalam memanfaakan potensi sebagai keunggulan daerah. Sehingga dalam penjelasan tersebut pengembangan wilayah berasis ekonomi akan menghasilkan peningkatan pembangunan yang bersinergi membangun daerah secara berkelanjutan.

\subsection{Komoditas Unggulan Subsektor Perkebunan}

Menurut Viradayanti (2018) komoditas unggulan adalah sektor yang memiliki hasil produksi komoditas yang cenderung meningkan dan stabil serta memiliki tingkat daya saing yang tinggi. Faktor peningkatan komoditas tumbuh secara tidak langsung menjadi faktor yang mempengaruhi kegiatan investasi dan menjadi subsektor yang memiliki tumpuan terhadap kegiatan ekonomi. Kriteria sektor unggulan akan berkembang sesuai dengan lingkup pembahasan penelitian dan menyeseuaikan terhadap lokasi penelitian. Sehingga dalam upaya peningkatan perekonomian masyarakat diperlukan pembentukan tahapan penggunaan faktor-faktor produksi 
sehingga menghasilkan proses pemanfaatan hasil subsektor perkebunan dengan menciptakan aliran timbal balik bagi masyarakat. Oleh karena itu, dalam penentuan komoditas unggulan dilakukan analisis dengan menggunakan perhitungan Location Quotient (LQ) dan Shift Share Analysis (SSA).

\section{Hasil dan Pembahasan}

\subsection{Analisis Location Quotient (LQ)}

Analisis menggunakan data time series yaitu perhitungan yang dimulai dari 2015, 2016, 2017, 2018, dan 2019. Jenis komoditas subsektor perkebunan pada Kecamatan Penajam yaitu Kelapa (kelapa dalam), Kelapa Sawit, Karetm dan Kopi. Ketentuan dalam analisis yaitu apabila nilai $L Q>1$ maka termasuk komoditas basis dengan pertumbuhan komoditas lebih besar dibanding wilayah lainnya, sedangkan nilai LQ $<1$ maka termasuk dalam komoditas non basis dengan pertumbuhan komoditas kecil dan hanya mampu memenuhi kebutuhan wilayahnya sendiri. Dengan digunakan data time series, maka hasil analisis yang didapatkan yaitu nilai ratarata LQ (Tabel 1).

Berdasarkan hal tersebut didapatkan hasil perhitungan bahwa seluruh komoditas yang terdiri dari komoditas kelapa, kelapa sawit, karet, dan komoditas kopi termasuk kedalam sektor basis. Dengan nilai ini dapat diidentifikasi bahwa komoditas yang memiliki niai $L Q>1$ menunjukkan tingkat lebih tinggi dibandingkan pada wilayah yang lainnya sehingga berpotensi sebagai komoditas yang strategis untuk dikembangkan. Berikut komoditas basis berdasarkan wilayah kelurahan/desa:

a. Kelapa (kelapa dalam): Penajam, Gunung Steleng, Sungai Parit, Tanjung Tengah, Saloloang, Sesumpu, Pejala, dan Kampung Baru.

b. Kelapa Sawit: Tanjung Tengah dan Riko.

c. Karet: Gunung Steleng, Nenang, Lawe-Lawe, Giripurwa, Girimukti, Pejala, Buluminung, Pantai Lango, dan Gersik.

d. Kopi: Nipah-Nipah.

Tabel 1. Hasil Perhitungan Nilai Rata-Rata LQ Menurut Kelurahan/Desa

\begin{tabular}{lrrrr}
\hline \multirow{2}{*}{ Kelurahan/Desa a } & \multicolumn{4}{c}{ Komoditas } \\
\cline { 2 - 5 } & Kelapa & Kelapa Sawit & Karet & Kopi \\
\hline Penajam & 21,66 & 0,20 & 0,00 & 0,00 \\
Gunung Steleng & 9,17 & 0,14 & 29,86 & 0,00 \\
Nenang & 0,22 & 0,19 & 17,73 & 0,00 \\
Sungai Parit & 14,18 & 0,10 & 0,00 & 75,53 \\
Nipah - Nipah & 0,28 & 0,17 & 0,00 & 0,00 \\
Lawe - Lawe & 0,00 & 0,14 & 21,83 & 0,00 \\
Giripurwa & 0,85 & 0,92 & 1,52 & 0,00 \\
Girimukti & 0,00 & 0,68 & 3,60 & 0,00 \\
Petung & 0,00 & 0,64 & 0,00 & 0,00 \\
Sidorejo & 0,98 & 0,84 & 0,00 & 0,00 \\
Tanjung Tengah & 12,01 & 1,06 & 0,22 & 0,00 \\
Saloloang & 27,55 & 0,28 & 0,00 & 0,00 \\
Sesumpu & 25,65 & 0,17 & 0,00 & 0,00 \\
Pejala & 4,00 & 0,53 & 7,61 & 0,00 \\
Kampung Baru & 20,96 & 0,02 & 0,00 & 0,00 \\
Buluminung & 0,61 & 0,18 & 61,49 & 0,00 \\
Sotek & 0,00 & 0,83 & 0,51 & 0,00 \\
Sepan & 0,18 & 0,48 & 0,34 & 0,30 \\
Riko & 0,00 & 1,08 & 6,89 & 0,00 \\
Bukit Subur & 0,00 & 0,40 & 0,27 & 0,00 \\
\hline
\end{tabular}




\begin{tabular}{lrrrr}
\hline \multirow{2}{*}{ Kelurahan/Desa } & \multicolumn{4}{c}{ Komoditas } \\
\cline { 2 - 5 } & Kelapa & Kelapa Sawit & Karet & Kopi \\
\hline Pantai Lango & 0,00 & 0,20 & 14,52 & 0,00 \\
Gersik & 0,20 & 0,03 & 15,54 & 0,00 \\
Jenebora & 0,00 & 0,21 & 0,00 & 0,00
\end{tabular}

\subsection{Shift Share Analysis (SSA)}

Tahapan lanjutan untuk mencapai hasil analisis komoditas unggulan, dilakukan analisis Shift Share (SSA) yang secara umum digunakan untuk mengukur peran sektor terhadap daerah (Fretes, 2017). Pada analisis ini terdapat beberapa proses analisis yaitu dengan menghitung rasio produksi dalam kurun waktu tahun 2015 - 2019. Perhitungan diawali dengan melakukan perhitungan nilai rasio seperti Rasio Produksi Subsektor Kelurahan dan Desa (ri), Rasio Produksi Subsektor Kecamatan (Ri), Rasio Total Produksi Subsektor Perkebunan Kecamatan (Ra). Hasil perhitungan nilai rasio, dilanjutkan dengan melakukan tahapan perhitungan Komponen Pertumbuhan Proporsional (KPP), Pertumbuhan Pangsa Wilayah (KPPW), dan Pergeresan Bersih (PB). Nilai $\mathrm{PB}>0$, artinya komoditas tersebut kedalam kelompok komoditas dengan pertumbuhan cepat sedangkan Nilai $\mathrm{PB}>0$, artinya komoditas tersebut kedalam kelompok komoditas dengan pertumbuhan cepat.

Berdasarkan perhitungan yang telah dilakukan didapatkan hasil komoditas kelapa sawit memiliki nilai PB positif lebih banyak dibandingkan dengan komoditas lainnya. Kemudian dilanjutkan dengan komoditas kelapa (kelapa dalam) dan komoditas karet yang masih memiliki nilai PB bernilai positif, namun pada hasil komoditas kopi tidak menghasilkan nilai PB yang bernilai positif. Sehingga berdasarkan hal tersebut, komoditas kelapa, kelapa sawit dan komoditas karet terhitung dari tahun 2015 - 2019 memiliki nilai pertumbuhan yang cepat dan progresif. Hasil perhitungan juga menunjukkan bahwa 3 (tiga) komoditas tersebut memiliki tingkat daya saing yang tinggi karena memiliki hasil perhitungan bernilai positif. Berikut hasil nilai perhitungan Shift Share (SSA):

a. Kelapa: Sungai Parit, Saloloang, dan Sepan

b. Kelapa Sawit: Nipah-Nipah, Lawe-Lawe, Giripurwa, Tanjung Tengah, Saloloang, Pejala, Sotek, dan Riko.

c. Karet: Sepan

Tabel 2. Hasil Interpretasi Nilai PB Menurut Kelurahan/Desa

\begin{tabular}{lcccc}
\hline \multirow{2}{*}{ Kelurahan/Desa } & \multicolumn{4}{c}{ Komoditas } \\
\cline { 2 - 5 } Kelapa & Kelapa Sawit & Karet & Kopi \\
\hline Gunung Steleng & $\mathrm{PB}=0$ & $\mathrm{~PB}=0$ & $\mathrm{~PB}=0$ & $\mathrm{~PB}=0$ \\
Nenang & $\mathrm{PB}=0$ & $\mathrm{~PB}=0$ & $\mathrm{~PB}=0$ & $\mathrm{~PB}=0$ \\
Sungai Parit & $\mathrm{PB}=0$ & $\mathrm{~PB}=0$ & $\mathrm{~PB}=0$ & $\mathrm{~PB}=0$ \\
Nipah - Nipah & $\mathrm{PB}>0$ & $\mathrm{~PB}<0$ & $\mathrm{~PB}=0$ & $\mathrm{~PB}=0$ \\
Lawe-Lawe & $\mathrm{PB}=0$ & $\mathrm{~PB}>0$ & $\mathrm{~PB}=0$ & $\mathrm{~PB}=0$ \\
Giripurwa & $\mathrm{PB}=0$ & $\mathrm{~PB}>0$ & $\mathrm{~PB}<0$ & $\mathrm{~PB}=0$ \\
Girimukti & $\mathrm{PB}=0$ & $\mathrm{~PB}=0$ & $\mathrm{~PB}=0$ & $\mathrm{~PB}=0$ \\
Petung & $\mathrm{PB}=0$ & $\mathrm{~PB}=0$ & $\mathrm{~PB}=0$ & $\mathrm{~PB}=0$ \\
Sidorejo & $\mathrm{PB}=0$ & $\mathrm{~PB}=0$ & $\mathrm{~PB}=0$ & $\mathrm{~PB}=0$ \\
Tanjung Tengah & $\mathrm{PB}=0$ & $\mathrm{~PB}>0$ & $\mathrm{~PB}=0$ & $\mathrm{~PB}=0$ \\
Saloloang & $\mathrm{PB}>0$ & $\mathrm{~PB}>0$ & $\mathrm{~PB}=0$ & $\mathrm{~PB}=0$ \\
Sesumpu & $\mathrm{PB}=0$ & $\mathrm{~PB}=0$ & $\mathrm{~PB}=0$ & $\mathrm{~PB}=0$ \\
Pejala & $\mathrm{PB}=0$ & $\mathrm{~PB}>0$ & $\mathrm{~PB}=0$ & $\mathrm{~PB}=0$ \\
Kampung Baru & $\mathrm{PB}=0$ & $\mathrm{~PB}=0$ & $\mathrm{~PB}=0$ & $\mathrm{~PB}=0$ \\
Buluminung & $\mathrm{PB}=0$ & $\mathrm{~PB}=0$ & $\mathrm{~PB}=0$ & $\mathrm{~PB}=0$ \\
\hline
\end{tabular}




\begin{tabular}{lcccc}
\hline \multirow{2}{*}{ Kelurahan/Desa } & \multicolumn{4}{c}{ Komoditas } \\
\cline { 2 - 5 } & Kelapa & Kelapa Sawit & Karet & Kopi \\
\hline Sotek & $\mathrm{PB}=0$ & $\mathrm{~PB}>0$ & $\mathrm{~PB}=0$ & $\mathrm{~PB}=0$ \\
Sepan & $\mathrm{PB}>0$ & $\mathrm{~PB}<0$ & $\mathrm{~PB}>0$ & $\mathrm{~PB}<0$ \\
Riko & $\mathrm{PB}=0$ & $\mathrm{~PB}>0$ & $\mathrm{~PB}=0$ & $\mathrm{~PB}=0$ \\
Bukit Subur & $\mathrm{PB}=0$ & $\mathrm{~PB}=0$ & $\mathrm{~PB}=0$ & $\mathrm{~PB}=0$ \\
Pantai Lango & $\mathrm{PB}=0$ & $\mathrm{~PB}=0$ & $\mathrm{~PB}=0$ & $\mathrm{~PB}=0$ \\
Gersik & $\mathrm{PB}=0$ & $\mathrm{~PB}=0$ & $\mathrm{~PB}=0$ & $\mathrm{~PB}=0$ \\
Jenebora & $\mathrm{PB}=0$ & $\mathrm{~PB}=0$ & $\mathrm{~PB}=0$ & $\mathrm{~PB}=0$
\end{tabular}

\subsection{Analisis Komoditas Unggulan}

Ketentuan dalam analisis komoditas unggulan merupakan hasil komulatif dari nilai LQ dan SSA pada perhitungan sebelumnya. Berdasarkan hasil komulatif output tersebut digunakan perhitungan dapat dinyatakan dengan klasifikasi komoditas unggulan ditunjukkan dengan nilai yang memiliki keunggulan kompatatif dengan nilai LQ > 1 dan kelompok progresif memiliki nilai PB > 0. Berdasarkan hasil analisis didapatkan bahwa komoditas unggulan pada Kecamatan Penajam yaitu Komoditas Kelapa dan Komoditas Kelapa Sawit (Tabel 3). Perhitungan nilai LQ menghasilkan nilai basis dengan terindentifikasi bahwa seluruh komoditas subsektor perkebunan di Kecamatan Penajam termasuk kedalam sektor basis. Pada hasil perhitungan SSA didapatkan nilai PB hanya komoditas kelapa, kelapa sawit dan karet yang memiliki nilai positif dengan klasifikasi sehingga komoditas tersebut termasuk kedalam komoditas dengan pertumbuhan tinggi atau progresif. Berikut interpretasi hasil komulatif dari analisis komoditas unggulan:

Tabel 3. Hasil Interpretasi Nilai Komoditas Unggulan

\begin{tabular}{lccc}
\hline \multicolumn{1}{c}{ Komoditas } & Nilai LQ & Nilai PB & Keterangan \\
\hline Kelapa & LQ $>1$ & PB $>0$ & Unggulan \\
Kelapa Sawit & LQ $>1$ & PB $>0$ & Unggulan \\
Karet & LQ $>1$ & PB $<0$ & Berkembang \\
Kopi & LQ $>1$ & PB $=0$ & Terbelakang
\end{tabular}

Interpretasi nilai didapatkan bahwa komoditas yang menjadi komoditas unggulan di Kecamatan Penajam yaitu komoditas kelapa (kelapa dalam) dan komoditas kelapa sawit. Pada komoditas kelapa (kelapa dalam) menjadi komoditas unggulan karena memiliki hasil komoditas yang menunjukkan nilai dengan produksi pertumbuhan komoditas yang lebih besar terhadap wilayah Kecamatan Penajam. Hal tersebut didukung oleh kondisi eksisting kelurahan dan desa pada Kecamatan Penajam memiliki sebagian wilayah berada di wilayah pesisir dengan peruntukan lahan perkebunan kelapa dalam. Hasil perhitungan komoditas unggulan kelapa dengan nilai positif dapat diartikan bahwa komoditas ini berpotensi secara berkelanjutan untuk memenuhi kebutuhan konsumsi kelapa serta mampu mendorong perekonomian untuk Kecamatan Penajam. Hasil komoditas lain, terdapat komoditas kelapa sawit yang menjadi komoditas unggulan kedua pada Kecamatan Penajam dengan hasil nilai pertumbuhan cepat dan memiliki daya saing yang lebih tinggi. Menghasilkan nilai positif maka dapat diartikan bahwa komoditas kelapa sawit juga berpotensi secara berkelanjutan untuk meningkatkan jumlah produksi kelapa sawit di Kecamatan Penajam. Komoditas kelapa sawit menjadi komoditas unggulan di Kecamatan Penajam karena memberikan kontribusi hasil produksi terbanyak dengan hasil panen dengan wilayah peruntukan lahan perkebunan kelapa sawit terbesar yaitu 6252,18 (ha).

Pada penelitian oleh Wulandari dan Kemal (2016), hasil komoditas unggulan kelapa sawit dapat memberikan kontribusi besar terhadap perkembangan ekonomi daerah. Selain itu hasil komoditas unggulan berpengaruh langsung untuk dapat menjadi penggerak ekonomi rakyat serta mampu membuka peluang kerja. Selain itu, pada hasil penelitian oleh Viradayanti (2018) pada wilayah Kecamatan Penajam menjadi kecamatan yang memiliki tipologi wilayah sebagai wilayah potensial untuk melakukan pengembangan kawasan industi perkebunan. Dengan kata lain, jika hasil produktivitas komoditas semakin meningkat serta proses pengolahan dan pemasaran hasil komoditas yang baik maka akan menghasilkan dampak pemanfaatan sumberdaya alam subsektor perkebunan secara maksimal terhadap pertumbuhan ekonomi daerah. 
Berdasarkan perhitungan komoditas unggulan didapatkan hasil analisis menurut kewilayahan kelurahan/desa di Kecamatan Penajam. Pada komoditas unggulan kelapa, memiliki nilai ungggul pada Kelurahan Sungai Parit dan Kelurahan Salaloang, sedangkan pada komoditas unggulan kelapa sawit unggul pada Kelurahan Tanjung Tengah dan Kelurahan Riko. Dengan demikian komoditas kelapa dan kelapa sawit pada 4 (empat) wilayah tersebut ditetapkan sebagai kawasan potensial untuk dilakukan sebagai pengembangan wilayah terhadap komoditas unggulan subsektor perkebunan. Hal tersebut didukung karena komoditas kelapa dan kelapa sawit merupakan komoditas yang menghasilkan pertumbuhan yang baik dan progresif serta memiliki daya saing yang tinggi sehingga mampu meningkatkan perekonomian Kecamatan Penajam hingga mendorong subsektor perkebunan di Kabupaten Penajam Paser Utara.

\section{Kesimpulan}

Hasil analisis yang dilakukan dalam penentuan komoditas unggulan subsektor perkebunan di Kecamatan Penajam Kabupaten Penajam Paser Utara adalah Komoditas Kelapa dan Komoditas Kelapa Sawit. Kondisi eksisting wilayah menujukkan bahwa Kecamatan Penajam memiliki potensi terhadap komoditas kelapa dan kelapa sawit. Hal tersebut didukung dengan luas penggunaan lahan pada komoditas kelapa sawit cenderung mengalami peningkatan disetiap tahunnya serta sebagian besar wilayah berada pada wilayah pesisir sebagai penghasil komoditas kelapa. Secara detail komoditas unggulan tersebar dibeberapa kelurahan/desa diantaranya: Kelurahan Sungai Parit dan Kelurahan Saloloang untuk komoditas kelapa, serta Kelurahan Tanjung Tengah dan Kelurahan Riko untuk komoditas kelapa sawit.

Berdasarkan data yang didapatkan komoditas unggulan subsektor perkebunan di Kecamatan Penajam tersebar dibeberapa wilayah. Dengan nilai produktifitas yang semakin meningkat dan memiliki daya saing yang tinggi maka direkomendasikan agar dapat dilakukan klaster atau pengelompokan daerah sebagai sentra kawasan produksi khusus komoditas unggulan subsektor pekebunan di Kecamatan Penajam. Melalui hal tersebut, perumusan klaster kemudian akan memaksimalkan hasil pemanfaatan komoditas subsektor perkebunan sebagai peningkatan ekonomi di Kecamatan Penajam.

\section{Referensi}

Data Base Ekonomi Kabupaten Penajam Paser Utara Tahun 2018. Dinas Komunikasi dan Informatika Kabupaten Penajam Paser Utara

Data Hasil Produksi Komoditas Subsektor Perkebunan Kecamatan Penajam, Kabupaten Penajam Paser Utara Tahun $2014-2019$.

Fretes, Pieter Noisirifan de. 2017. Analisis Sektor Unggulan (LQ), Struktur Ekonomi (Shift Share), dan Proyeksi Produk Domestik Regional Bruto Provinsi Papua 2018. Papua: Sekolah Tinggi Ilmu Ekonomi Ottow \& Geissler Serui

Mustikaningrum, Indri dan Widjonarko. 2018. Komoditas Unggulan Tanaman Pangan Untuk Mendukung Perekonomian Wilayah Kabupaten Indramayu. Semarang: Universitas Diponegoro

Rencher, Alvin C. 2002. Methods of Multivariate Analysis: Second Edition. Canada: A John Wiley \& Sons, INC

Ridwan. 2016. Pembangunan Ekonomi Regional. Yogyakarta: Pustaka Puitika

Riyadi, Ahmad dan Andri, Kuntoro Boga. 2015. Analisis Kinerja Sektor Pertanian dalam Pengembangan Wilayah di Provinsi Sulawesi Barat. Agrise: Sulawesi Barat

Viradayanti, Rina Artha. 2018. Arahan Pengembangan Kawasan Industri Pertanian Berdasarkan Tipologi Wilayah di Kabupaten Penajam Paser Utara (Studi Kasus: Subsektor Tanaman Pangan). Insitut Teknologi Kalimantan

Widjayatnika, Benadikta $d k k$. 2017. Analisis Perubahan Penggunaan Lahan Dan Arahan Pemanfaatan Ruang Untuk Pertanian Di Kabupaten Penajam Paser Utara, Provinsi Kalimantan Timur. Journal of Regional and Rural Development Planning: IPB

Wulandari, Siti Abir dan Kemala Nida. 2016. Kajian Komoditas Unggulan Sub-Sektor Perkebunan di Provinsi Jambi. Jurnal Ilmiah: Universitas Batanghari Jambi

Wulandari, Wanda. 2015. Peranan PDRB Sub-Sektor Perkebunan Terhadap Pertumbuhan Ekonomi di Kabupaten Bolaang Mongondow. Manado: Universitas Sam Ratulangi 